\title{
Back analysis of the Vaiont slide using a multi- block sliding model
}

\author{
C. Stamatopoulos \& S. Aneroussis \\ Stamatopoulos and Associates Co, Athens, Greece
}

\begin{abstract}
A multi-block sliding system model and associated computer code has been developed to model the displacement of sliding geo-masses. This model is a useful tool, especially when displacements are very large and computer codes based on the Finite Element Method cannot be applied. The paper applies the model to predict the response of the well-documented Vaiont landslide, which occurred on 9 October 1963. The predicted deformation of the slide and backestimated soil strength agreed reasonably well with the measured. In addition the computed and observed time duration of motion and peak slide velocity are in agreement.
\end{abstract}

Keywords: Vaiont slide, multi-block model, residual soil strength.

\section{Introduction}

The conventional sliding-block model has shortcomings in back-analyzing slides when displacement is large. The reason is that the change on geometry of the sliding mass, that greatly affects the displacement, is not modeled. Ambraseys and Srbulov [1] proposed a two-body sliding system that models the displacement of slides. Stamatopoulos et al. [2] generalized the two-body sliding system. Sarma and Chlimintzas [3] proposed a sliding system consisting of $n$ bodies. Similarly to the Sarma [4] stability analysis method, internal sub-planes are formed at the locations where the external slip surface changes inclination. Energy loss at these sub-planes is adequately modeled. As shear displacement occurs, mass is transferred between consecutive blocks.

This model is a useful tool, especially when displacements are very large and computer codes based on the Finite Element Method cannot be applied. The purpose of this paper is to investigate the ability of the model to predict the 
response of the well-documented Vaiont landslide, which occurred on 9 October 1963.

\section{The multi-block model}

\subsection{Geometry}

We consider a general mass sliding in n slip surfaces. Similarly to the geometry considered in the Sarma's [4] stability method, shown in fig 1, the mass in divided to $n$ parts with (n-1) interfaces passing thru the nodes of the slip surface. Critical acceleration factor, $\mathrm{k}_{\mathrm{c}}$, is the minimum factor that when multiplied by the acceleration of gravity, $\mathrm{g}$, gives the horizontal acceleration which is just sufficient to cause movement of the block. The inclinations of the interfaces correspond to the inclinations that produce failure at a minimum value of $\mathrm{k}_{\mathrm{c}}$. (This condition is preferred from the commonly-used factor of safety factor because it is better defined).

At the interface between two consecutive blocks, the velocity must be continuous. This principle gives that the relative displacement of the $n$ bodies is related to each other as:

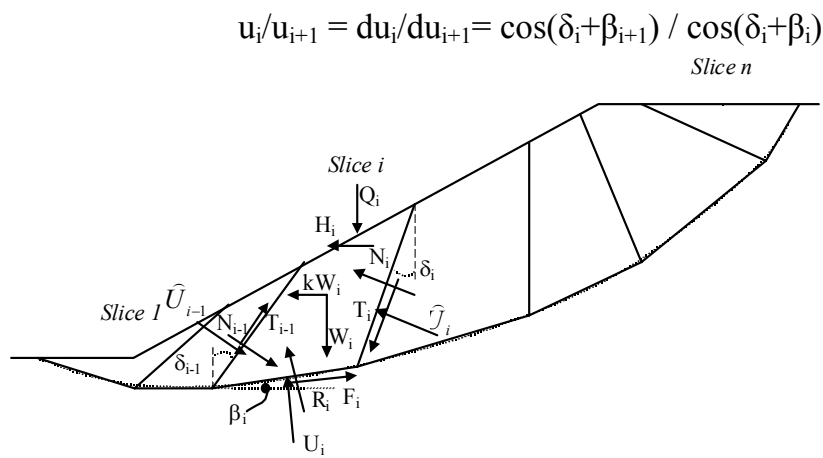

Figure 1: $\quad$ The multi-block stability method proposed by Sarma [4].

\subsection{Applied forces and equations of motion}

The forces that are exerted in body "i" are given in fig. 2. As the body moves, at the external slip surfaces, the Mohr Coulomb failure criterion gives

$$
\mathrm{F}_{\mathrm{i}}=\left(\mathrm{R}_{\mathrm{i}}-\mathrm{U}_{\mathrm{i}}\right) \tan \varphi_{\mathrm{i}}+\mathrm{c}_{\mathrm{i}} \mathrm{l}_{\mathrm{i}}
$$

At the internal slip surfaces it gives

$$
\mathrm{T}_{\mathrm{i}}=\left(\mathrm{N}_{\mathrm{i}}-\mathrm{U}_{\mathrm{in}-\mathrm{i}}\right) \tan \varphi_{\mathrm{in}-\mathrm{i}}+\mathrm{c}_{\mathrm{in}-\mathrm{i}} \mathrm{b}_{\mathrm{i}}
$$


where $U_{i}, \varphi_{i}$ and $c_{i}$ are the pore pressure and the frictional and cohesional components of resistance of the external slip surface $i$ respectively and $U_{\text {in-i }}, \varphi_{\text {in-i }}$ and $\mathrm{c}_{\mathrm{in}-\mathrm{i}}$ are the pore pressure and frictional and cohesional components of resistance of the internal slip surfaces i respectively.

From the above equations, the equation of motion of body (i) along the direction of motion, is formulated. To eliminate the internal forces $N_{i}$ we multiply the (i) equation by a factor. Summing all equations and expressing displacement of all blocks in terms of $u_{n}$, we obtain the equation of motion. As the equations are very long, they are not presented here. They are presented by $[3]$.

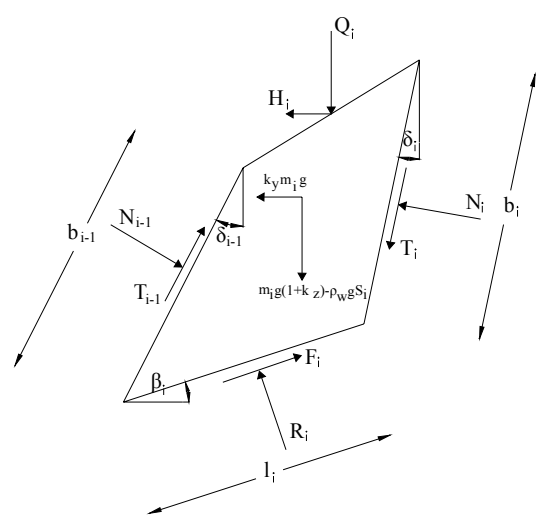

Figure 2: $\quad$ Forces at body "i”".

\subsection{Changes of areas and lengths as a function of the distance moved}

To solve, we need to express the masses and lengths of each body $\mathrm{i}$ in terms of the distance moved. We apply the transformation rule that predicts that when each block is displaced by $d \tilde{u}_{i}$, each point of the block including the ground surface (at the top of the block) is also displaced by dũ $\tilde{i}_{i}$. This rule must be applied incrementally because a point may move from one block to the previous, and thus its incremental displacement will change from du $\tilde{u}_{i}$ to dũ $\tilde{u}_{i-1}$. Based on this rule, the masses areas and lengths of the bodies "i" of the sliding system are continually updated as a function of the distance moved. The deformation that this rule predicts in a two-body system is illustrated in fig. 3 .

\subsection{Computer program}

A computer program that solves the equations of motion of the model described above has been developed by Stamatopoulos. The input geometry is specified as the nodes of the linear segments defining the slip and ground surfaces. The inclinations of the internal slip surfaces are also defined. Soil strength and pore pressures are specified in each segment. The computer program includes 
graphics that illustrate (a) the acceleration, velocity and displacement in terms of time and (b) the final deformation of the slide that the model predicts.

(a)

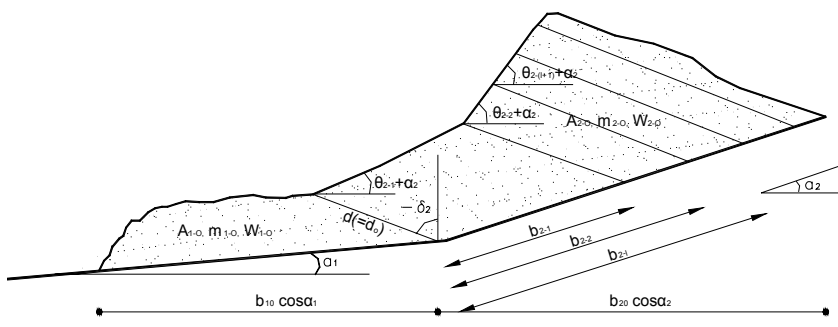

(b)

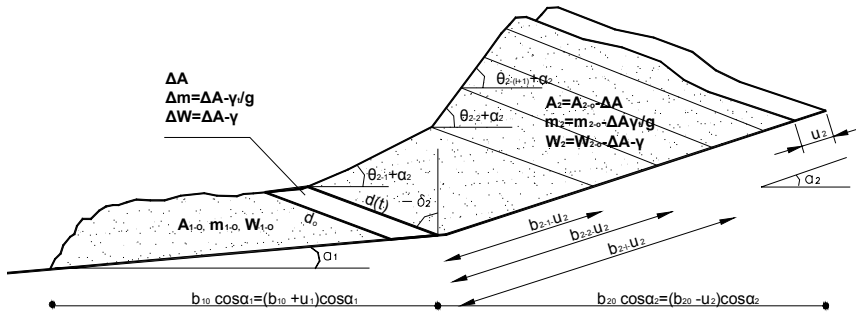

Figure 3: Deformation assumed in the model. The case of a 2-body sliding system is given: (a) Initial position, (b) position when the distance moved by the second body is $\mathrm{u}_{2}$ (Stamatopoulos et al. [2]).

\section{The Vaiont slide}

The Vaiont landslide occurred on 9 October 1963 and has been the subject of numerous studies [6, 7, 8]. A $250 \mathrm{~m}$ thick earth mass, approximately 250 million $\mathrm{m}^{3}$ in volume, moving with a very high velocity, plunged into the reservoir at its foot, displacing most of the impounded water over the Vaiont arch dam. The sliding lasted less than $1 \mathrm{~min}$. The sliding mass slid some $400 \mathrm{~m}$ at an estimated velocity of $20-30 \mathrm{~m} / \mathrm{s}$. The initial and deformed slide geometry at a typical cross-section of the slide is given in fig. 4.

Change in water table due to dam construction may have played a role in activating the slide. The initial reactivation of the landslide is readily explicable by considering it as a renewal of movement in a ancient landslide, on a preexisting slip surface at or close to the residual strength, as indicated by the geological evidence [7]. This ancient slide may have followed pre-existing tectonic shears [7]. The water table elevation at the reservoir is at $+650 \mathrm{~m}$ with rain, while at the lower part of the slide it is at elevation of about $+700 \mathrm{~m} \mathrm{[8]}$. 


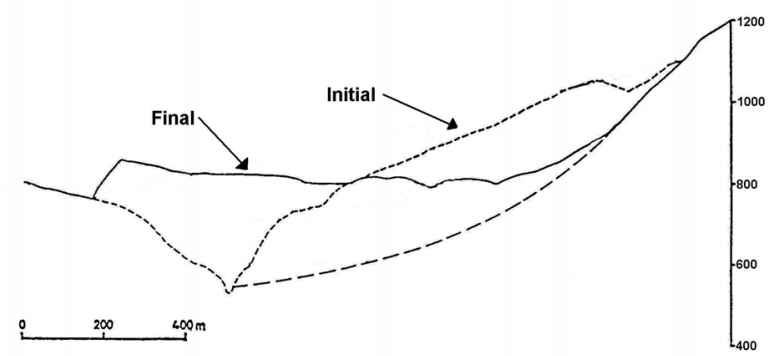

Figure 4: Typical cross-section of the Vaiont slide (Section 3, Ciabati [5]).

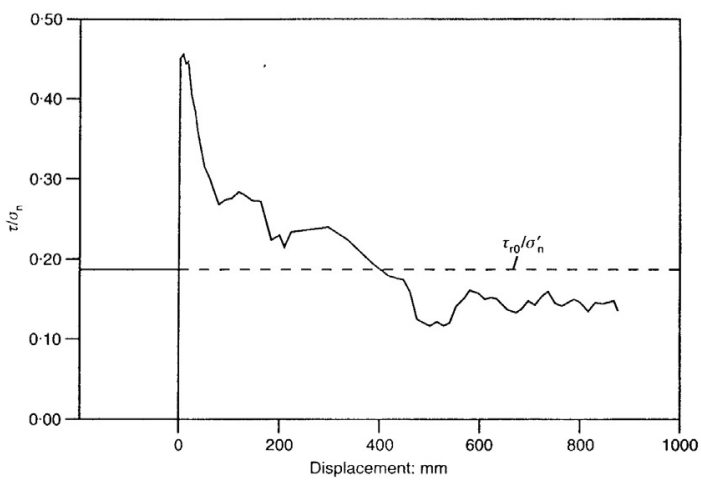

Figure 5: Typical measured response of ring shear tests on samples from the Vaiont slide - No C (Tika and Hutchinson [7]).

Table 1: $\quad$ Results of ring shear tests on soil from Vaiont landslide [7].

\begin{tabular}{|c|c|c|c|c|c|c|}
\hline No & Sample & $\begin{array}{l}\text { Speed } \\
(\mathrm{mm} / \mathrm{min})\end{array}$ & $\begin{array}{l}\left(\tau / \sigma_{0}^{\prime}\right)_{\mathrm{ma}} \\
x\end{array}$ & $\begin{array}{l}\left(\tau / \sigma_{0}^{\prime}\right)_{\mathrm{re}} \\
\mathrm{s}\end{array}$ & $\begin{array}{l}\mathrm{u}(\mathrm{mm}) \\
\text { at } \\
\left(\tau / \sigma_{0}^{\prime}\right)_{\max }\end{array}$ & $\begin{array}{l}\text { u }(\mathrm{mm}) \\
\text { at } \\
\left(\tau / \sigma_{0}^{\prime}\right)_{\mathrm{ma}} \\
x\end{array}$ \\
\hline A & 4 & 0.0145 & 0.48 & 0.18 & 10 & 600 \\
\hline B & 3 & 0.0145 & 0.48 & $\begin{array}{ll}0.18 \\
\end{array}$ & 10 & 600 \\
\hline $\mathrm{C}$ & 4 & 2600 & 0.47 & 0.15 & 10 & 600 \\
\hline D & 4 & $"$ & 0.40 & 0.10 & 10 & 600 \\
\hline $\mathbf{E}$ & 3 & $"$ & 0.43 & 0.15 & 10 & 600 \\
\hline $\mathbf{F}$ & 3 & $"$ & 0.35 & 0.10 & 10 & 800 \\
\hline
\end{tabular}


Recently, Tika and Hutchinson [7] performed ring shear tests on soil from the Vaiont landslide slip surface. Test results are given in fig. 5 and table 1 . The measured normalized residual soil strength $\left(\tau / \sigma_{0}^{\prime}\right)_{\text {res }}$ equals 0.10 to 0.20 . The corresponding total friction angle is 6 to 10 degrees (table 2). The measured normalized peak soil strength $\left(\tau / \sigma_{o}^{\prime}\right)_{\max }$ equals 0.35 to 0.46 . The corresponding total friction angle is 19 to 25 degrees, or about 2 to 3 times larger than the residual friction angle.

Table 2: $\quad$ Analysis of strength of the fast tests of the results of table 1.

\begin{tabular}{|l|l|l|l|}
\hline No & $(\varphi)_{\max }$ & $(\varphi)_{\text {res }}$ & $(\varphi)_{\max } /(\varphi)_{\text {res }}$ \\
\hline A & 25.7 & 10.2 & 2.5 \\
\hline B & 25.7 & 10.2 & 2.5 \\
\hline C & 25.2 & 8.5 & 3.0 \\
\hline D & 21.8 & 5.7 & 3.8 \\
\hline E & 23.3 & 8.5 & 2.7 \\
\hline F & 19.3 & 5.7 & 3.4 \\
\hline
\end{tabular}

\section{Steps used to apply the multi-block model}

The steps required to apply the multi-block model in back analyses of slides are: (a) The slip surface is located and simulated as a series of linear segments, (b) the inclination of the internal linear segments is established according to the condition of minimum critical acceleration value and (c) the distance moved and slide deformation is estimated using the multi-block model.

The above procedure assumes that soil strength is known. In the present study a range of measured soil strength values exists. For this reason, for steps (b) and (c) the following procedure is used: (1) Guess a soil strength, (2) Estimate the inclinations of the internal sub-planes based on the theory of limit equilibrium for this resistance, (3) Back-estimate the soil strength that best predicts the final deformed geometry, (4) Compare the back-estimated resistance with the resistance assumed in (1) and if it is different, perform again steps (2) to (4) until convergence is achieved. Finally, compare the back-estimated resistance with the measured range of strength values.

\section{Prediction}

The slip surface of the slide (fig. 4) was simulated by four linear segments, as shown in fig 7. Consistently with the triggering factor, pore pressures were applied. Their magnitude, was taken from a distribution given by [8]. In particular, the average pore pressure was taken as $0.0,100.0,150.0$ and $40.0 \mathrm{kPa}$ at the slices 1 to 4 respectively, from left to right, of the slip surface. The unit weight of the soil was taken as $2 \mathrm{~T} / \mathrm{m}^{3}$.

Uniform strength was taken along the slip surface, corresponding to the residual strength value. At the interfaces, for shearing to occur, the peak strength 
must be reached. Thus, according to measurements, a value of soil strength higher by a factor of about 3 was used.

The procedure described in section 4 was used to obtain the solution of the problem. Fig. 6 gives the critical acceleration coefficient for relative motion at the initial configuration in terms of the three interface angles. It can be observed that the interface angles that produce minimum critical acceleration value are $\delta_{1}=0^{\circ}, \delta_{2}=-33^{\circ}, \delta_{3}=-30^{\circ}$. For these values the best-fit final geometry obtained is given in fig 7. The strength corresponds to $(\varphi)_{\text {res }}=9^{\circ}$ and $(\varphi)_{\max }=27^{\circ}$. Fig 8 gives the computed acceleration, velocity and distance moved of the upper body in terms of time of the solution above. The computed time duration of motion and peak velocity are $27 \mathrm{~s}$ and $22 \mathrm{~m} / \mathrm{s}$ respectively.

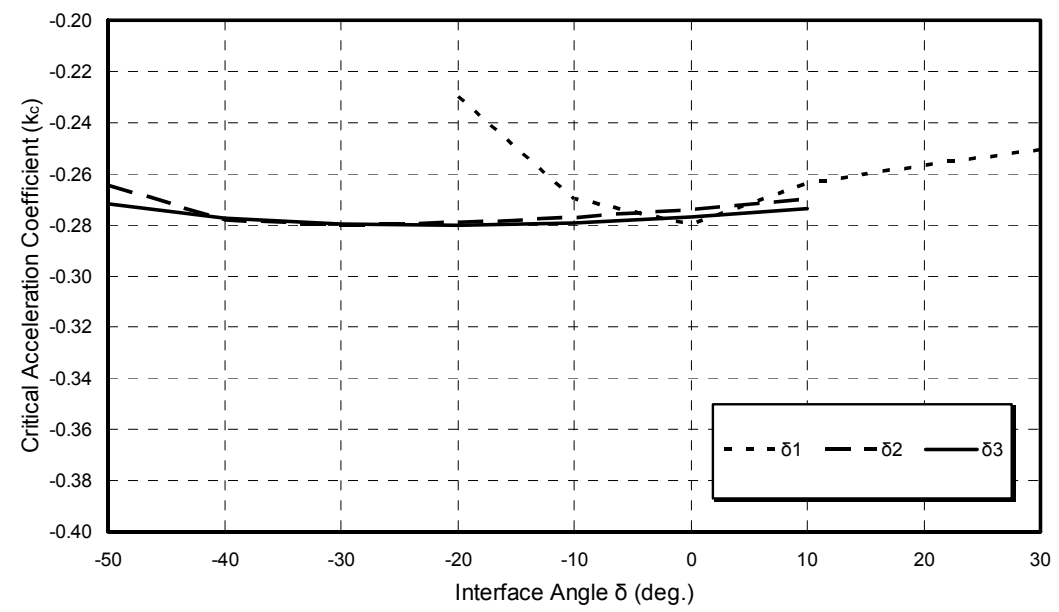

Figure 6: Critical acceleration coefficient for relative motion at the initial configuration in terms of the three interface angles. For each case the other two interface angles equal to their critical values.

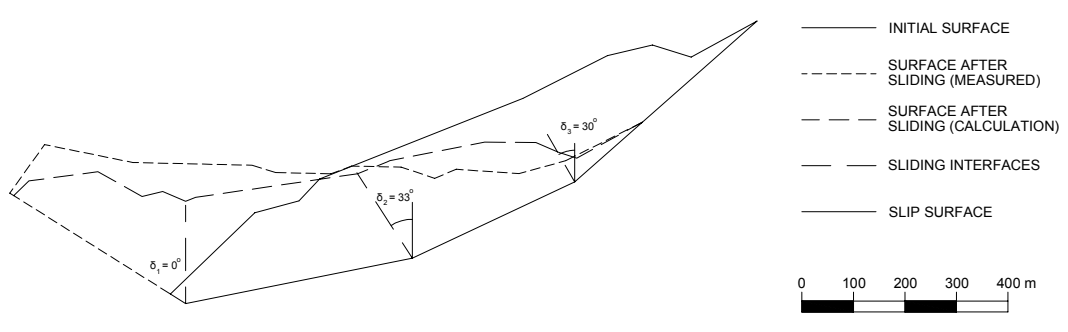

Figure 7: Initial slide configuration assumed, computed final configuration and measured final configuration. 


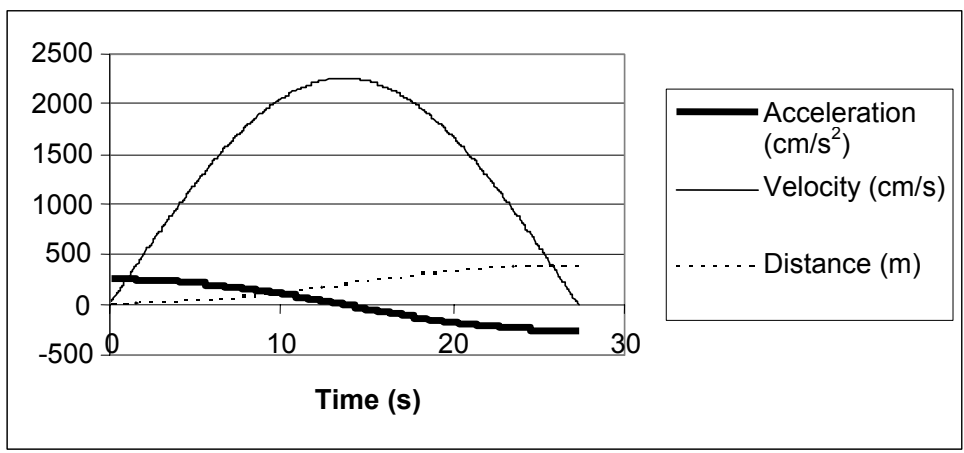

Figure 8: Computed acceleration, velocity and distance moved of the upper body in terms of time.

\section{Discussion}

The computed deformed geometry agrees reasonably with the measured. The back-estimated soil strength is a little larger than the range of the measured values at the average slide velocity, that, according to table 2 equals to about $8.1^{\circ}$. This is consistent with observations of previous slides where the estimated value for the residual internal friction angle of 2D analyses is systematically higher than the real (Georgopoulos and Vardoulakis [9]). The reason for this is that analyses are 2D and 3D effects are not considered.

The computed time duration of motion and peak slide velocity agree with the observed values of less than $1 \mathrm{~min}$ and $20-30 \mathrm{~m} / \mathrm{s}$ respectively. From all the above it is inferred that the multi-block model can be used to simulate the motion and deformation of the Vaiont slide.

\section{Conclusions}

A multi-block sliding system model and associated computer code has been developed to model the displacement of sliding geo-masses. The paper investigated the ability of the model to predict the response of the welldocumented Vaiont landslide, which occurred on 9 October 1963. The predicted deformation of the slide and back-estimated soil strength agreed reasonably well with the measured. In addition the computed and observed time duration of motion and peak slide velocity are in agreement.

\section{Acknowledgement}

This work was supported by the Project Risk Mitigation for Earthquakes and Landslides (LESSLOSS) (Project No. GOCE-CT-2003-505448) funded by the European Commission. 


\section{References}

[1] Ambraseys N., Srbulov M., Earthquake induced displacements of slopes, Soil Dynamics and Earthquake Engineering; 14, pp. 59-71, 1995

[2] Stamatopoulos C., Velgaki E., and Sarma S., Sliding-block back analysis of earthquake-induced slides. Soils and foundations, The Japanese Geotechnical Society, Vol. 40, No. 6, pp 61-75, 2000.

[3] Sarma, S. K. and Chlimintzas, G, Analysis of seismic displacement of slopes using multi-block model. Final report performed under the grant of the European Commission Project ENV4-CT97-0392, January, 2001.

[4] Sarma, S. K., Stability analysis of embankments and slopes, Journal of Geotechnical Engineering ASCE, Vol.105, 12, pp. 1511-1524, 1979.

[5] Ciabati, M., La dinamica della frana del Vaiont, G. Geol, Vol 32, pp 139154, 1964.

[6] Hendron, A. J. \& Patton, F. D., The Vaiont slide, a Geotechnical analysis based on new geologic observations of the failure surface, Technical report GL-85-5, Dept. of the Army US Corps of Engineers, Washington, DC 20314-1000, 1985.

[7] Tika, T. E. and Hutchinson, J N., Ring shear tests on soil from the Vaiont landslide slip surface, Geotechnique, 59-74, 1999.

[8] Tika, T. E., The consideration of rate effect on the residual strength for the displacement prediction of landslides, Proceedings of the 3th Hellenic Conference on Geotechnical Engineering, Patras, Vol. 2, pp293-300 (in Greek), 1997.

[9] Georgopoulos, I. O., Vardoulakis, I., Study of the Malakasa Landslide of 182-1995 by using combined block failure mechanisms, Proceedings of the 4th Hellenic Conference on Geotechnical and Geonvironmental Engineering, Athens, 2001. 